\title{
PLANEJAMENTO ESTRATÉGICO DE DESENVOLVIMENTO PARA A REGIÃO DO COREDE MISSÕES/RS-BRASIL
}

Daniel Claudy da Silveira ${ }^{1}$ Berenice Beatriz Rossner Wbatuba² Luis Claúdio Villani Ortiz ${ }^{3}$

Resumo: O estudo contempla a operacionalização do Plano Estratégico de Desenvolvimento Regional (PEDR) da região das Missões do Estado do Rio Grande do Sul. O objetivo é apresentar os aspectos relativos à atualização do PEDR do Corede Missões, que teve como prerrogativa o processo de inserção e participação da sociedade, sob forma de plenárias municipais e macrorregionais e suas percepções de desenvolvimento do território. A metodologia utilizada resgatou os conceitos provenientes da matriz F.O.F.A., de modo a identificar potencialidades, desafios, ameaças e oportunidades em seis eixos de análise. Além disso, estabeleceu-se a estratégia de hierarquização do processo de escolhas dos agentes regionais envolvidos, sendo para isso utilizada a matriz de Vester, que permitiu determinar problemas críticos e ativos, requerendo maior atenção e uma rápida formulação de alternativas de correção, prevenção e controle das ações do PEDR. Nesse contexto, com a participação e legitimação por parte da sociedade regional, identificou-se quatro (4) estratégias regionais, inseridas em cinquenta e seis projetos (56) e ações futuras, hierarquizadas, de modo a possibilitar aos atores sociais, a implementação de alternativas para o desenvolvimento da Região do Corede Missões.

Palavras-chave: Plano Estratégico de Desenvolvimento Regional (PEDR). Corede Missões. Matriz FOFA. Estratégia de Hierarquização. Matriz de Vester.

\section{STRATEGIC DEVELOPMENT PLANNING FOR THE COREDE MISSIONS REGION/RS-BRAZIL}

Abstract: The study contemplates the operationalization of the Regional Development Strategic Plan (PEDR) of the Missions region of the State of Rio Grande do Sul. The objective is to present the aspects related to the updating of the PEDR of Corede Missões, which had as prerrogative the process of insertion and participation of society, in the form of municipal and macro regional plenaries and their perceptions of territorial development. The methodology used rescued the concepts from the F.O.F.A. matrix, in order to identify potentialities, challenges, threats and opportunities in six axes of analysis. In addition, the hierarchical strategy of the process of choices of the regional agents involved was established. The Vester matrix was used to determine critical and active problems, requiring more attention and a rapid formulation of alternatives for correction, prevention and control of PEDR's actions. In this context, with the participation and legitimacy of the regional

\footnotetext{
1 Universidade Regional do Noroeste do Estado do Rio Grande do Sul (UNIJUÍ), Departamento de Ciências Administrativas, Contábeis, Econômicas e da Comunicação (DACEC), Santo Ângelo/RS; ljuí/RS, Brasil, danielsilveira@san.uri.br; daniel.silveira@unijui.edu.br, https://orcid.org/0000-00034379-6144.

2 Universidade Regional Integrada do Alto Uruguai e das Missões (URI/Campus Santo Ângelo), Departamento de Ciências Sociais, Santo Ângelo/RS, Brasil, bwbatuba@san.uri.br, https://orcid.org/0000-0002-1496-5634.

3 Instituto Federal Goiano (IFG), Departamento de Ciências sociais Aplicadas, Iporá/GO, Brasil, Icvortiz@gmail.com, https://orcid.org/0000-0003-3566-1602.
} 
society, four (4) regional strategies were identified, inserted in fifty-six projects (56) and future actions, hierarchical, in order to enable social actors to implement alternatives for the development of the Region of Corede Missões.

Key-words: Regional Development Strategic Plan (PEDR). Corede Missões. Matrix FOFA. Hierarchical Strategy. Matrix of Vester.

\section{PLANIFICACIÓN ESTRATÉGICA DE DESARROLLO PARA LA REGIÓN DE MISIONES NORMALES / RS-BRASIL}

Resumen: El estudio contempla la operacionalización del Plan Estratégico de Desarrollo Regional (PEDR) de la región de Misiones del Estado de Rio Grande do Sul. El objetivo es presentar los aspectos relacionados con la actualización del PEDR de Corede Missões, que tuvo la inserción y participación de la sociedad, en forma de sesiones plenarias municipales y macrorregionales y sus percepciones del desarrollo territorial. La metodología utilizada rescató los conceptos de la matriz F.O.F.A., para identificar potencialidades, desafíos, amenazas y oportunidades en seis ejes de análisis. Además, se estableció la estrategia de jerarquía del proceso de elección de los agentes regionales involucrados, utilizando la matriz de Vester, que permitió determinar problemas críticos y activos, requiriendo una mayor atención y una formulación rápida de alternativas de corrección, prevención y control de acciones PEDR. En este contexto, con la participación y legitimación de la sociedad regional, se identificaron cuatro (4) estrategias regionales, insertadas en 56 proyectos (56) y acciones futuras, jerárquicas, para permitir a los actores sociales, la implementación de alternativas para el desarrollo de la Región Corede Missões.

Palabras-clave: Plan Estratégico de Desarrollo Regional (PEDR). Ejecutar misiones; Matriz de FOFA. Estrategia de jerarquización. Matriz Vester.

\section{INTRODUÇÃO}

O processo de atualização do Plano Estratégico de Desenvolvimento Regional (PEDR) teve como objetivo elaborar um documento que reunisse as diferentes estratégias e interesses dos atores sociais, baseado na participação da sociedade, possibilitando um amplo debate e um espaço privilegiado de negociação, confrontando e articulando divergências e convergências dos atores regionais.

Nesse contexto, o PEDR das Missões construiu um diagnóstico técnico, através do levantamento de dados regionais considerando nove (09) aspectos relevantes, tais como: geografia, demografia, história, meio ambiente, economia, social e cultural, institucional, turismo e infraestrutura.

O processo de atualização do PEDR do Corede Missões foi realizado através de plenárias municipais e macro regionais, a partir da metodologia da matriz F.O.F.A., identificando potencialidades, desafios, ameaças e oportunidades em seis eixos de análise diferentes: infraestrutura, social e cultural, econômico, turístico, ambiental e institucional. 
Além da elaboração da matriz F.O.F.A., pelos eixos elencados, foram estabelecidos escalas de priorização das demandas, e, a partir delas, a definição das estratégias e seus respectivos projetos de desenvolvimento. Para isso, a estratégia de hierarquização deu-se através da implementação da matriz de Vester. Assim, tornou-se possível evidenciar as problemáticas erguidas nas reuniões com a sociedade, contemplando as inter-relações existentes e estabelecendo uma relação de causa-efeito dos entraves diagnosticados. Após a elaboração da matriz de Vester, optou-se por classificar as problemáticas em quadrantes: Problemas Críticos, Problemas Passivos, Problemas Indiferentes e Problemas Ativos.

A metodologia da Matriz de Vester estabeleceu desse modo, uma escala de prioridade, considerando os problemas com maior grau de efeito-causalidade. A definição das estratégias do PEDR das Missões, por meio da operacionalização metodológica anteriormente exposta, identificou campos de análise que apresentam carências latentes, apontadas pelo regramento metodológico, e assim, influenciando ações e projetos de melhoria relacionados a ampliação da qualidade de vida da sociedade regional.

Como delineamento final deste artigo, dentro do contexto apresentado e metodologias aplicadas, os problemas identificados transformaram-se em projetos e ações definidas em quatro grandes estratégias que possibilitaram aos atores sociais buscar alternativas de desenvolvimento para a Região do Corede Missões.

O artigo está dividido, além dessa seção introdutória, em mais cinco seções, que são: a) a primeira refere-se à caracterização do território em estudo; b) a segunda trata do processo de construção do PEDR Missões e sua estrutura de gestão; c) a terceira destaca a abordagem metodológica aplicada para a definição de estratégias e prioridades regionais; d) e a última seção apresenta algumas considerações finais em relação ao objeto de estudo. 


\section{CARACTERIZAÇÃO DA REGIÃO DO COREDE MISSÕES/RS}

O Conselho Regional de Desenvolvimento (Corede) das Missões foi criado em $1991^{4}$ e integra a Região Funcional de Planejamento Sete (RFP 7) ${ }^{5}$ do Estado do Rio Grande do Sul. A RFP 7 reúne os Corede's Celeiro, Missões, Fronteira Noroeste e Noroeste Colonial (Figura 01).

Figura 01- Região Funcional de Planejamento Sete (RFP 7)

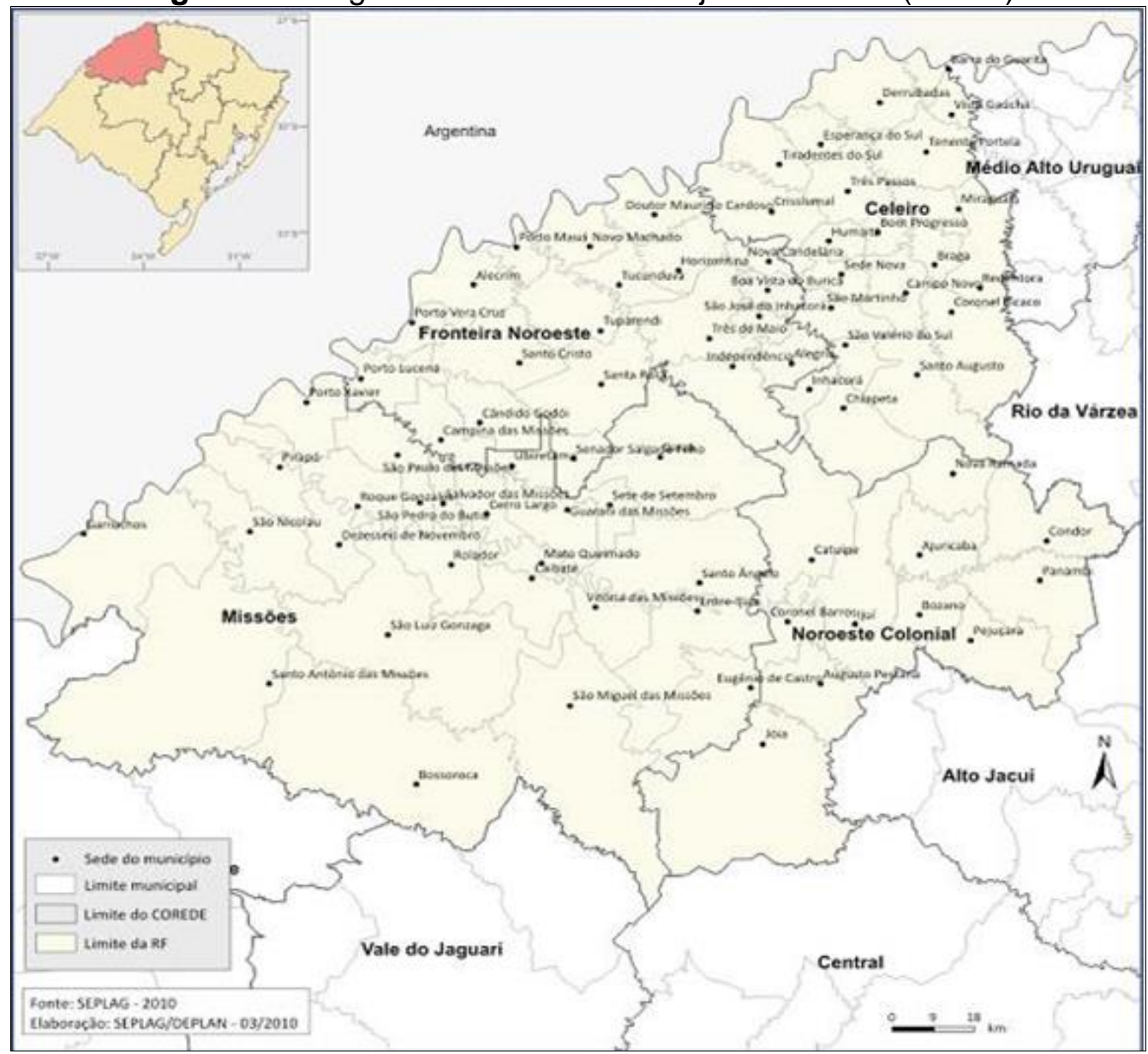

Fonte: SEPLAN, 2015.

De acordo com o COREDE Missões (2010, p. 23) a região engloba vinte e cinco (25) municípios, listados a seguir: Bossoroca, Caibaté, Cerro Largo, Dezesseis de Novembro, Entre-ljuís, Eugênio de Castro, Garruchos, Giruá, Guarani das Missões, Mato Queimado, Pirapó, Porto Xavier, Rolador, Roque Gonzales, Salvador

\footnotetext{
${ }^{4}$ Legalmente reconhecidos, através de decreto estadual, em 1994, mas estabelecidos em 1991, como instrumento de "enfrentamento de problemas relacionados com a dinâmica territorial. Nesse sentido, uma das primeiras iniciativas institucionais para construir uma estratégia de ação para o desenvolvimento regional" (SEPLANRS/DEPLAN, 2015. p.6).

${ }^{5}$ As regiões funcionais de planejamento foram propostas pelo Estudo de Desenvolvimento Regional e Logística do Rio Grande do Sul - Rumos 2015, contratado em 2003 pela Secretaria da Coordenação e Planejamento, a partir do agrupamento de Corede's, como uma escala mais agregada que possibilita o tratamento de temas de interesse regional. A regionalização, juntamente com a do Corede's, passou a ser utilizada para o planejamento das ações governamentais, no orçamento do Estado e no plano plurianual (SEPLAN, 2015, p. 08).
} 
das Missões, Santo Ângelo, Santo Antônio das Missões, São Luiz Gonzaga, São Miguel das Missões, São Nicolau, São Paulo das Missões, São Pedro do Butiá, Sete de Setembro, Ubiretama e Vitória das Missões.

Localiza-se na Região Noroeste do Estado do Rio Grande do Sul, limitandose ao Norte com o Corede-Fronteira Noroeste, ao Leste com o Corede-Noroeste Colonial, ao Sul com o Corede-Vale do Jaguari, a Sudoeste com o Corede-Fronteira Oeste e no Extremo-Oeste com a República da Argentina (Figura 02). Sua área total corresponde a 4,6\% do território do Estado do Rio Grande do Sul. Suas altitudes variam de 70 a 360 metros distribuídos predominantemente na unidade geomorfológica do Planalto Meridional (COREDE MISSÕES, 2010, p. 23).

Figura 02- Mapa Geográfico da Região das Missões

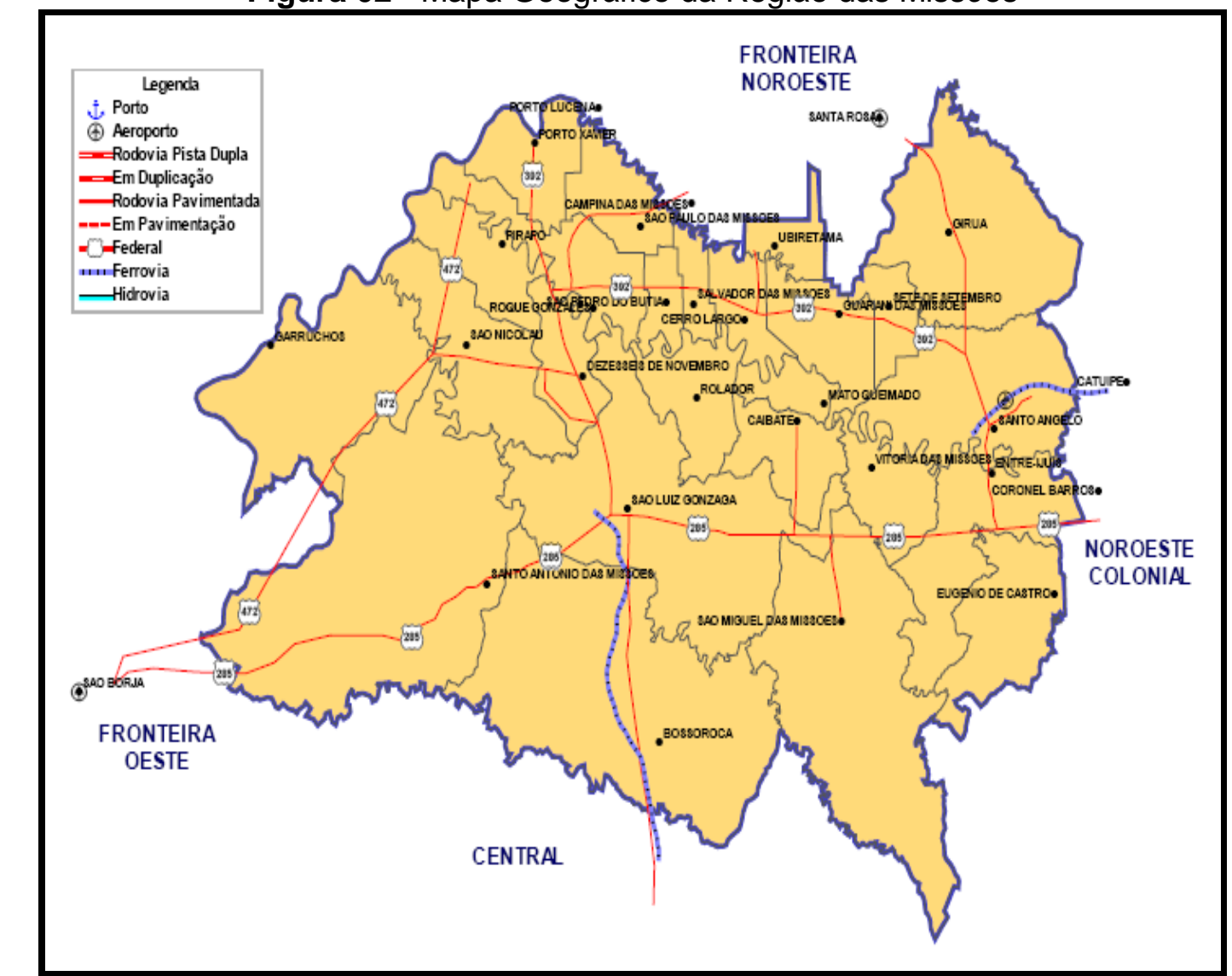

Fonte: Consórcio B Allen - Rumos 2015 (2005).

Conforme a SEPLAN (2015, p. 08) embora o Corede Missões possua proximidade física em relação ao território Argentino, o mesmo não apresenta uma economia integrada com a região de fronteira argentina, contribuindo para isso a falta de infraestrutura de ligação na área separada pelo Rio Uruguai.

Em relação à economia regional, o Corede Missões possui uma base econômica voltada à agropecuária (SEPLAN, 2015, p. 08), em que se destaca a pecuária, e o cultivo de grãos, como milho, trigo, e, principalmente, soja. Por sua 
vez, a indústria, está ligada ao beneficiamento de produtos primários e, comércio e serviços, estão voltados ao abastecimento e suporte ao setor primário e secundário provenientes da agropecuária. Outro importante ativo da região é o turismo histórico e cultural, bem como potenciais físico-naturais ainda inexplorados.

As características físico-naturais da região missioneira estão inseridas na classificação faunística WALLACE, localizando-se na região neotropical, representado por uma grande variedade de aves, répteis, anfíbios, mamíferos e insetos (COREDE MISSÕES, 2010, p. 24).

Quanto à flora, seus municípios inserem-se na Bacia Hidrográfica do Rio Uruguai e nas Sub-bacias do Rio ljuí, Rio Comandaí, Rio Piratini, Rio Buricá, e Rio Santa Rosa. Além disto, pertencem ao Bioma Pampa (campos nativos ao Sul e Sudoeste da região - basicamente com presença de atividades pastoris) e Bioma Mata Atlântica (áreas de florestas no Centro, Norte e Leste da região - produção de grãos), com ampla diversidade de plantas e vegetais (BERNARDES, 1997).

Conforme se observa na Figura 03, os municípios com maiores extensões de terras encontram-se no centro-sul, leste e sudoeste da região missioneira. Entre eles, destacam-se Bossoroca, São Luiz Gonzaga, Santo Antônio das Missões, São Miguel das Missões, Giruá e Garruchos. Os outros municípios são detentores de uma área territorial média e pequena, localizados no centro-norte e noroeste da região. 
Figura 03- Municípios do Conselho Regional de Desenvolvimento do Corede Missões

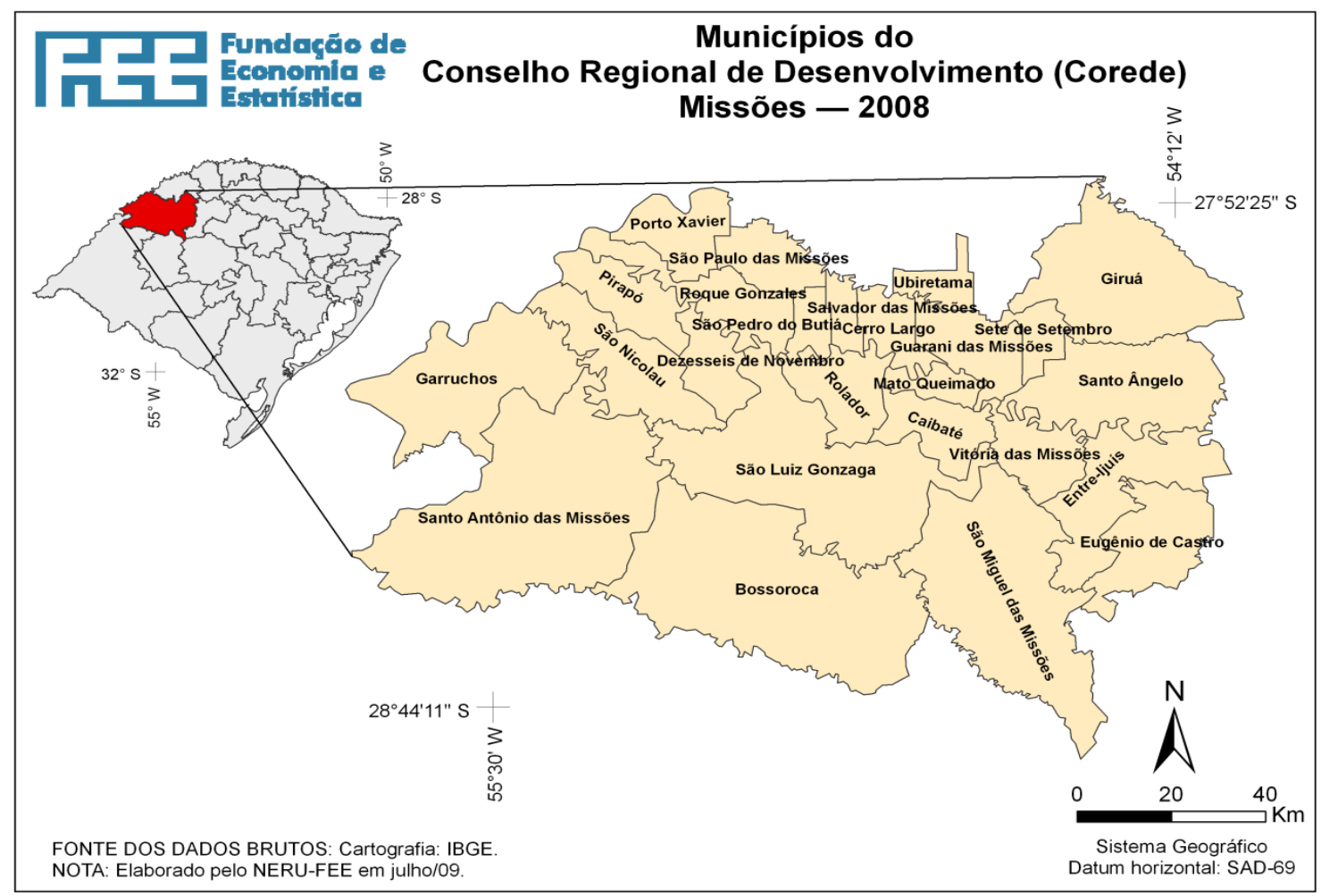

Fonte: Fundação de Economia e Estatística do Estado do Rio Grande do Sul - FEE/RS.

É importante salientar que a fronteira estabelecida com a República da Argentina se estende ao longo do Rio Uruguai, que banha os municípios de Porto Xavier, Roque Gonzales, Pirapó, São Nicolau e Garruchos.

Por outro lado, em relação às características de relevo e solos, a região é dotada de áreas de planalto no Leste, Centro-Sul e Sudoeste das Missões. O Centro-Norte apresenta características de relevo mais acidentado, com interferência de rios e mananciais. E, no Oeste, há predominância de uma característica singular, com a ocorrência de um microclima distinto, que está presente ao longo da encosta do Rio Uruguai (COREDE MISSÕES, 2010).

Segundo o Instituto Brasileiro de Geografia e Estatística (IBGE), a Região possui um Centro Sub-Regional ${ }^{6}$ (Santo Ângelo), dois Centros de Zona ${ }^{7}$ (São Luiz Gonzaga e Cerro Largo) e os demais municípios como Centros Locais ${ }^{8}$. Santo Ângelo atrai os dois Centros de Zona e os Centros Locais próximos. Outros Centros

\footnotetext{
${ }^{6}$ Caracterizado como centros com atividades de gestão menos complexas, com área de atuação reduzida, com relacionamentos externos apenas com as metrópoles (SEPLAN, 2015, p. 09).

${ }^{7}$ Entendido como cidades de menor porte e com atuação restrita à sua área imediata (SEPLAN, 2015, p. 09).

${ }^{8}$ Definido como cidades cuja centralidade e atuação não extrapolam os limites do seu município, têm população predominantemente inferior a dez mil habitantes (SEPLAN, 2015, p. 09).
} 
Locais, localizados no Oeste da região, possuem ligações com São Luiz Gonzaga, e no Norte da região, com Cerro Largo (SEPLAN, 2015).

Em 2010, o Corede possuía uma população de 248.016 habitantes, que segundo a Fundação de Economia e Estatística - FEE (2016) representa 2,3\% da população total do Rio Grande do Sul.

O principal centro urbano do Corede é Santo Ângelo, com uma população de 76.275 habitantes. Em segundo plano, aparece São Luiz Gonzaga, com 34.556 habitantes. Os municípios de Giruá, Cerro Largo, Santo Antônio das Missões e Porto Xavier detêm entre 10 e 17 mil habitantes. Os demais municípios do Corede são de pequeno porte, com população girando em torno de 2 a 9 mil habitantes (FEE, 2016). O Quadro 01 demonstra a distribuição da população total, por municípios, por gênero, por taxa de urbanização e por densidade demográfica do Corede Missões.

De acordo com o Quadro 01, nota-se que, no ano de 2010, há uma maior concentração de habitantes no ambiente urbano, representando $70,91 \%$ do total, contra $29,09 \%$ no ambiente rural. A tendência é de que os municípios mais populosos, como Santo Ângelo, São Luiz Gonzaga, Giruá e Cerro Largo, puxem a taxa de urbanização de toda a região. No entanto, municípios com menores representatividades populacionais ainda são predominantemente rurais, tais como: Vitórias das Missões, Ubiretama, Sete de Setembro, Dezesseis de Novembro, Rolador, Mato Queimado e Pirapó. 
Quadro 01- População do Corede Missões - por município - 2010

\begin{tabular}{|c|c|c|c|c|c|c|c|}
\hline Municípios & População & Homens & Mulheres & Urbana & Rural & \begin{tabular}{c|} 
Taxa de \\
urbanização (\%) \\
\end{tabular} & $\begin{array}{c}\text { Densidade demografica } \\
\left(\mathrm{hab} / \mathbf{k m}^{2}\right)\end{array}$ \\
\hline Bossoroca & 6.884 & 3.509 & 3.375 & 3.682 & 3.202 & 53,49 & 4,3 \\
\hline Caibaté & 4.954 & 2.532 & 2.422 & 2.745 & 2.209 & 55,41 & 19,1 \\
\hline Cerro Largo & 13.289 & 6.617 & 6.672 & 10.571 & 2.718 & 79,55 & 74,8 \\
\hline Dezesseis de Novembro & 2.866 & 1.469 & 1.397 & 667 & 2.199 & 23,27 & 13,2 \\
\hline Entre-Íjuis & 8.938 & 4.415 & 4.523 & 4.893 & 4.045 & 54,74 & 16,2 \\
\hline Eugênio de Castro & 2.798 & 1.415 & 1.383 & 1.480 & 1.318 & 52,89 & 6,7 \\
\hline Garruchos & 3.234 & 1.682 & 1.552 & 1.057 & 2.177 & 32,68 & 4,0 \\
\hline Giruá & 17.075 & 8.338 & 8.737 & 12.907 & 4.168 & 75,59 & 20,0 \\
\hline Guarani das Missões & 8.115 & 3.951 & 4.164 & 5.030 & 3.085 & 61,98 & 27,9 \\
\hline Mato Queimado & 1.799 & 902 & 897 & 479 & 1.320 & 26,63 & 15,7 \\
\hline Pirapó & 2.757 & 1.398 & 1.359 & 777 & 1.980 & 28,18 & 9,5 \\
\hline Porto Xavier & 10.558 & 5.300 & 5.258 & 5.210 & 5.348 & 49,35 & 37,6 \\
\hline Rolador & 2.546 & 1.318 & 1.228 & 608 & 1.938 & 23,88 & 8,6 \\
\hline Roque Gonzales & 7.203 & 3.622 & 3.581 & 3.087 & 4.116 & 42,86 & 20,8 \\
\hline Salvador das Missões & 2.669 & 1.377 & 1.292 & 1.094 & 1.575 & 40,99 & 28,4 \\
\hline Santo Ângelo & 76.275 & 36.586 & 39.689 & 71.804 & 4.471 & 94,14 & 112,2 \\
\hline Santo Antônio das Missões & 11.210 & 5.579 & 5.631 & 6.788 & 4.422 & 60,55 & 6,6 \\
\hline São Luiz Gonzaga & 34.556 & 16.827 & 17.729 & 30.508 & 4.048 & 88,29 & 26,7 \\
\hline São Miguel das Missões & 7.421 & 3.880 & 3.541 & 3.727 & 3.694 & 50,22 & 6,0 \\
\hline São Nicolau & 5.727 & 2.906 & 2.821 & 3.692 & 2.035 & 64,47 & 11,8 \\
\hline São Paulo das Missões & 6.364 & 3.228 & 3.136 & 2.199 & 4.165 & 34,55 & 28,4 \\
\hline São Pedro do Butiá & 2.873 & 1.456 & 1.417 & 1.209 & 1.664 & 42,08 & 26,7 \\
\hline Sete de Setembro & 2.124 & 1.082 & 1.042 & 494 & 1.630 & 23,26 & 16,3 \\
\hline Ubiretama & 2.296 & 1.183 & 1.113 & 500 & 1.796 & 21,78 & 18,1 \\
\hline Vitória das Missões & 3.485 & 1.794 & 1.691 & 669 & 2.816 & 19,20 & 13,4 \\
\hline COREDE Missões & 248.016 & 122.366 & 125.650 & 175.877 & 72.139 & - & - \\
\hline
\end{tabular}

Fonte: elaborado pelos autores com base em dados da FEE (2016).

Percebe-se ainda, que a população está distribuída em 25 municípios com uma área de 12.844,10 km², apresentando uma densidade demográfica média de 19,40 habitantes $/ \mathrm{km}^{2}$. Este fato reflete a presença de médias e grandes propriedades, onde predominam a rarefação populacional, com baixas densidades. Estes municípios estão localizados ao sul e sudeste da região, como Garruchos com apenas 4,0 hab./km², Bossoroca com 4,3 hab./km², São Miguel das Missões com 6,0 hab./km², Santo Antônio das Missões com 6,6 hab. $/ \mathrm{km}^{2}$, Eugênio de Castro 6,7 hab./km², Rolador 8,6 hab. $/ \mathrm{km}^{2}$ e Pirapó com 9,5 hab./km². Os municípios mais densamente povoados são Santo Ângelo com 112,2 hab./km², Cerro Largo com 74,8 hab./km², e Porto Xavier com 37,6 hab./km², que estão acima da média regional.

Observam-se grandes contrastes na densidade demográfica dos municípios pertencentes ao território missioneiro. Por exemplo, em Santo Ângelo está concentrada 30,75\% da população da região, enquanto que em São Luiz Gonzaga 13,93\%; Giruá 6,88\% e; Cerro Largo 5,35\%, somados representam aproximadamente $57 \%$ do total regional, em 2010. Ou seja, nos municípios restantes (21 municípios) concentram-se uma população de aproximadamente $43 \%$ do Corede Missões. 
De acordo com estudos da Secretaria de Planejamento, Mobilidade e Desenvolvimento Regional - SEPLAN (2015) do Estado, o Rio Grande do Sul, é o estado brasileiro cuja população teve o menor crescimento populacional nos últimos anos. Observa-se, no território gaúcho, uma área que ocupa a fronteira norte, noroeste e parte do sul que se caracteriza pelo esvaziamento populacional, principalmente do setor rural. O Corede Missões é a região com a maior taxa de perda populacional. As maiores perdas populacionais estão na área rural, conforme dados da FEE (2016).

Depois de uma breve caracterização do território em análise, na seção seguinte são apresentadas as discussões teóricas acerca da relevância de elaboração de planos estratégicos de desenvolvimento regional e o processo de construção dos mesmos a nível estadual e regional.

\section{O PROCESSO dA ATUALIZAÇÃO DO - PEDR MISSÕES E SUA ESTRUTURA DE GESTÃO}

$\mathrm{O}$ desenvolvimento regional deve considerar as particularidades $\mathrm{e}$ especificidades regionais, que são instrumentos que podem levar ao desenvolvimento em uma perspectiva territorial. A região é o resultado de como o território se organiza e a regionalização é a construção do próprio processo e das particularidades na interação com a totalidade. Sendo que a totalidade é objeto de interação/construção, considerando as suas especificidades históricas, culturais, sociais, econômicas, políticas, geográficas e ambientais (ETGES, 2005).

Nestas condições, o desenvolvimento regional se dá a partir de planejamentos e/ou das ações nos territórios construídos, apropriados pela sociedade, ou seja, é no território que se constroem regiões ou lugares. Segundo Etges (2005), é nesse processo de apropriação e pertencimento que as regiões e os territórios emergem.

Portanto, não é possível ficar unicamente atrelado à percepção da ciência normal, que no caso das regiões seriam os planejamentos estratégicos, e dos paradigmas que impõe, mas sim de promover o desenvolvimento regional a partir das particularidades e territorialidades regionais (KUHN, 2011).

Além disto, o estilo de desenvolvimento a ser perseguido por uma política pública implica em escolhas (nunca neutras), que ao integrarem os aspectos socioeconômicos e ambientais na sua formulação e implementação determinam 
também as diretrizes e prioridades a serem observadas pelos atores institucionais envolvidos (FILIPPIM E RÓTULO, 2013).

Dessa forma, o estilo de desenvolvimento assim como o plano estratégico de desenvolvimento, depende da agenda a ser construída entre os governos e a sociedade, em diferentes escalas, com vistas à definição de políticas públicas, sua implantação e avaliação de resultados. Para Becker (1995), a governança regional deve articular-se para a proposição de políticas que promovam resultados com interconexão dos pressupostos que viabilizem um desenvolvimento sustentável, convertendo-se em políticas de Estado e, não apenas, de Governo.

Filippim e Rótulo (2013) destacam que a definição de um modelo de desenvolvimento norteador é tarefa, portanto, do conjunto social e não apenas dos governos (central, estadual, municipal). Neste mesmo sentido, essa abordagem parte da ideia de que se tornam necessários dois requisitos para que as políticas implementadas consigam ser bem-sucedidas. O primeiro requisito, refere-se a coordenação multinível dos diversos atores de governo e administrativos (federal, regional, estadual, sub-regional, local, etc.) que participam da política. E, o segundo, evidencia a coordenação intersetorial transversal desses mesmos atores que atuam nas distintas áreas das políticas públicas (saúde, educação, economia, meio ambiente, etc.). Além disso, é necessária uma visão integrada de diferentes dimensões de sustentabilidade para o desenvolvimento, sendo relevante considerar o espaço no qual ele se efetiva especialmente na sua configuração regional.

Deve haver uma interação entre os níveis da sociedade, tanto político quanto histórico, cultural, econômico, ecológico e social, dentro de um contexto territorial. O planejamento deve contemplar estas escalas de análise, de modo a aproximar o plano de sua efetividade. Se por um lado, isto não ocorre, a tendência é que se elaborem planos de governo, através de um sistema top down ao invés de botton up, de construção de um planejamento (BOISIER, 1995).

Assim, para Siedenberg (2010), um plano estratégico de desenvolvimento regional é um documento que contemporiza diagnóstico, prognóstico e ações a serem implementadas, considerando aspectos econômicos, sociais, ambientais, políticos, éticos, culturais, territoriais, entre outros. Visa identificar aspectos internos positivos (Fortalezas) e negativos (Fraquezas), e, aspectos externos positivos (Oportunidades) e negativos (Ameaças), que possibilitem identificar potencialidades e desafios, de modo que órgãos competentes possam propor estratégias e ações para o desenvolvimento. 
Conforme Cardoso Jr. e Melo (2011) e Rezende (2011), um plano de desenvolvimento é um esquema coerente e fundamentado de objetivos, de metas quantitativas e qualitativas, bem como de ações com caráter econômico, social e político. Caracterizados pela elaboração de diagnóstico, de instrumentos que possibilitem a implementação, de revisão e de correção das ações.

Possibilita visualizar aspectos centrais da sociedade e viabilizar caminhos, delineando orientações gerais que oportunizam escolhas entre as diversas políticas públicas. Para Cardoso Jr. e Melo (2011, p.17), os "dois eixos de um plano são uma visão abrangente da sociedade e uma formulação interligada das diversas políticas públicas e atividades de governo".

Conforme Cardoso Jr. e Melo (2011, p. 18) e Rezende (2011) a participação social é constituída, desde a participação via democracia representativa dos legislativos, até a participação das sociedades civis. Nestas condições, o plano de desenvolvimento é um mapa de rumos para o futuro, que pretende servir de marco de orientação, e, por isso mesmo, é um marco de discussão visando o desenvolvimento.

O plano estratégico de desenvolvimento regional, configura-se em um documento que contemporiza diagnóstico, prognóstico e ações/projetos a serem implementados, o qual deve considerar as particularidades e especificidades históricas, econômicas, sociais, ambientais, políticas, éticos, culturais e territoriais. Visa identificar fortalezas e fraquezas, e, oportunidades e ameaças (matriz F.O.F.A.), que possibilitem estabelecer potencialidades e desafios, a serem superados e contornados, de modo a propor estratégias e ações para o desenvolvimento territorial (SIEDENBERG, 2010).

Para a realização de um PEDR, a dinâmica de desenvolvimento da região deve estar conectada a um pensamento competitivo, que, no entanto, precisa estar dissociada da lógica teórica das vantagens comparativas dos economistas clássicos, a qual está baseada na disponibilidade de recursos naturais de determinada região em relação à outra. $O$ pressuposto competitivo do PEDR deve considerar as fortalezas e fragilidades, tanto nos âmbitos social, político, econômico, cultural, ético, dentro de um contexto competitivo, de processos, de produtos, de pessoas, de gestão, de capital social, entre outros. Nesta perspectiva, a região deve aproveitar sua competitividade, com base nas suas dotações estruturais e naturais de modo a organizá-las e potencializá-las, buscando a fortificação e a consolidação de seu desenvolvimento regional. 
Quanto à estrutura de gestão e trabalho para o processo de atualização do PEDR dos Corede's do Rio Grande do Sul, as mesmas foram definidas por debates e orientações consensuadas pelo Fórum dos Corede's, ao longo do primeiro semestre do ano de 2016. As coordenações regionais e equipes de trabalho estruturaram esse processo de atualização, organizados por comissões que abordaram questões territoriais, sendo estas classificadas em seis eixos temáticos.

Estes seis eixos temáticos consideraram os aspectos infraestruturais, socioculturais, econômicos, turísticos, ambientais e institucionais da região do Corede Missões, através de assembleias municipais e regionais, e posteriormente, por cada eixo (setorial) para a atualização do plano estratégico de desenvolvimento regional.

Em seu propósito, a gestão da atualização do plano visou obter dados nos seis (6) eixos temáticos sobre a região missioneira e, informações dos atores sociais para a elaboração de estratégias articuladas de desenvolvimento e monitoramento das ações a serem executadas nos programas e projetos regionais. Esta estrutura participativa de atualização envolveu: Associação dos Municípios das Missões AMM; Poderes Legislativos; Órgãos dos Poderes Executivos e Judiciários; COMUDES - Conselhos Municipais de Desenvolvimento; Associações Comerciais, Clubes de Dirigentes Lojistas; Sindicatos Patronais; Sindicatos dos Trabalhadores; Cooperativas Regionais; Universidades, Faculdades e Centros de Ensino, e; Organizações Não Governamentais (ONG's).

Portanto, um PEDR estruturado em diferentes perspectivas (políticas, econômicas, sociais, territoriais, culturais, entre outros) depende da capacidade de articulação entre estes, de modo a definir suas prioridades regionais.

Além disso, o plano deve servir como referência para que se direcionar e programar planos de governo, em uma perspectiva de médio e longo prazo, em diferentes níveis escalares. Assim, devem-se estabelecer bases de interação e articulação entre setor público e privado, instituindo metas para investimento público, isto, de forma conjunta com decisões de produção, investimento e emprego de recursos pelos agentes do setor privado.

Na próxima seção apresentam-se o regramento metodológico, estratégias de hierarquização e a operacionalização do respectivo estudo, com o objetivo de construir o processo a atualização do PEDR Missões. 


\section{METODOLOGIA E ESTRATÉGIA DE HIERARQUIZAÇÃO DO PEDR MISSÕES/RS}

O plano estratégico de desenvolvimento regional ora proposto enfatizou o Corede Missões. Assim, elaborou-se um diagnóstico técnico regional (sistematização dos dados), baseado em dados secundários dos aspectos considerados mais relevantes, tais como: geográficos, demográficos, históricos, ambientais, econômicos, socioculturais, institucionais, turísticos e de infraestrutura.

Para tal, utilizou-se de documentos regionais, diagnósticos e planos anteriores, através de uma análise situacional. De acordo com Siedenberg (2010, p. 48), "a análise situacional configura uma etapa crucial no processo de planejamento, até porque é uma espécie de transição entre passado (diagnóstico técnico) e futuro (prognóstico político)". Na Figura 04, consta a síntese das etapas desenvolvidas no PEDR das Missões.

Figura 04- Síntese das Etapas do Plano Estratégico de Desenvolvimento Regional

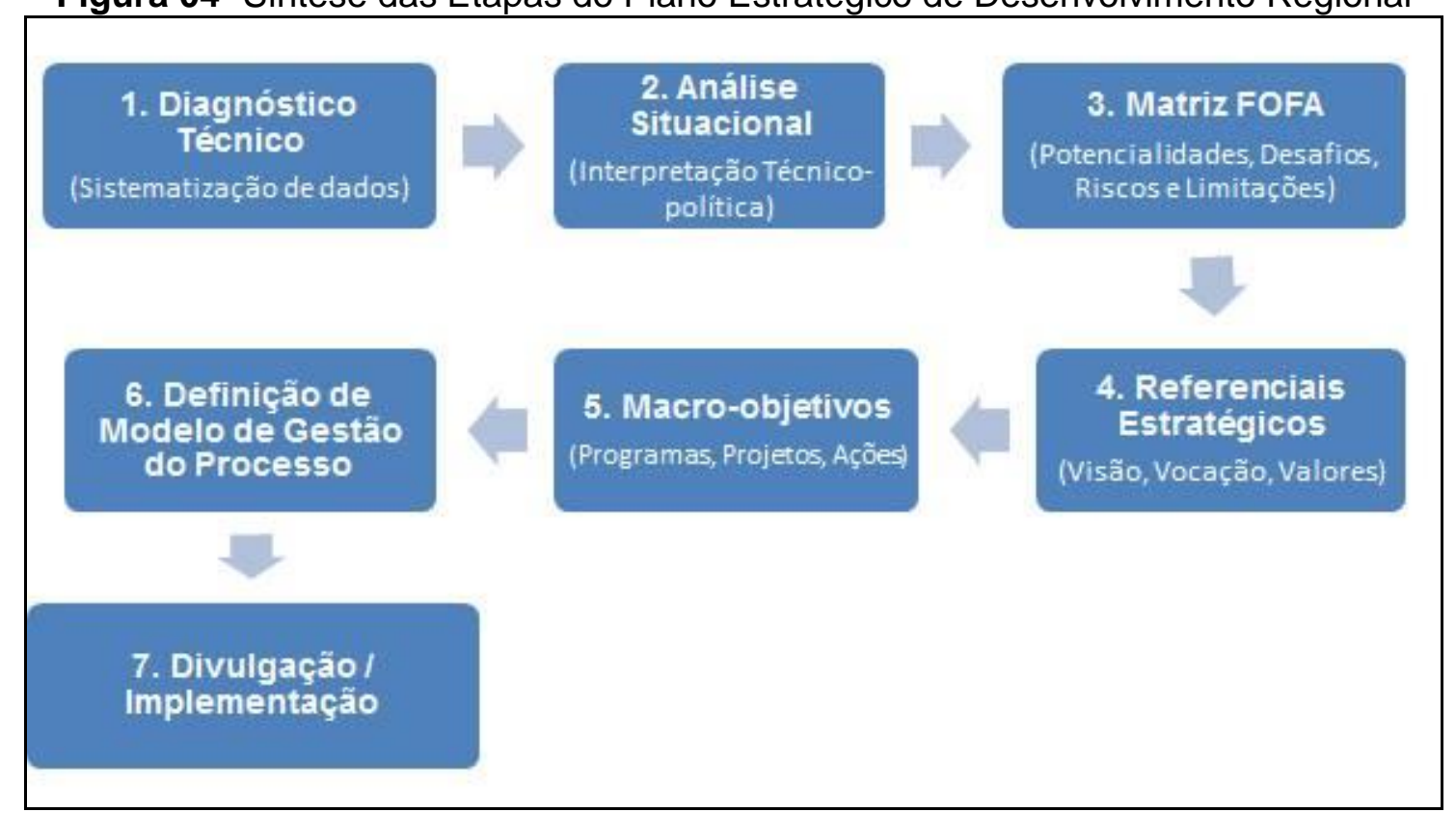

Fonte: Adaptado de Siedenberg (2010, p. 52).

Por sua vez, a etapa posterior, tratou sobre a elaboração da matriz F.O.F.A. do Corede Missões. Conforme Siedenberg (2010, p. 66):

[...] o termo FOFA, frequentemente relacionado as ferramentas de gestão e planejamento organizacional, tem origem no acrônimo inglês, conhecido por matriz ou Análise SWOT, cujos termos acabaram sendo traduzidos ao português como Forças (Strenghs), Oportunidades (Opportunities), Fraquezas (Weakenesses) e Ameaças (Threaths).

A matriz F.O.F.A. (Figura 05) foi construída a partir de aspectos internos e externos, de modo a identificar as potencialidades, desafios, riscos e limitações do Corede Missões. 
Figura 05- Representação Metodológica da Matriz F.O.F.A.

\begin{tabular}{|c|c|c|c|}
\hline \multicolumn{1}{|c|}{ MATRIZ FOFA } & FATORES DE ORIGEM INTERNA \\
\hline \begin{tabular}{c|c} 
FATORES DE \\
ORIGEM EXTERNA
\end{tabular} & OPORTUNIDADES & PORTALEZAS & FRAQUEZAS \\
\hline
\end{tabular}

Fonte: Adaptado de Siedenberg (2010, p. 67).

Para tanto, o objetivo da terceira etapa do processo de atualização do PEDR é de construir coletivamente - com base no diagnóstico técnico, na análise situacional da região e na leitura do cenário externo - uma visão apropriada das principais potencialidades, limitações, riscos e desafios regionais. Para tanto, é necessário identificar com muita clareza se os fatores F.O.F.A. são de origem interna ou externa, considerando sempre que alguns fatores externos podem representar tanto ameaças quanto oportunidades (SIEDENBERG, 2010).

Para Siedenberg (2010), quando se tratar de um processo de planejamento estratégico territorial envolvendo toda uma região (vários municípios), o ideal seria tentar elaborar a matriz, isto é, definir potencialidades, limitações, riscos e desafios, num primeiro estágio, a partir de percepções locais e setoriais, para que, num segundo estágio, fosse sistematizada a F.O.F.A. regional-setorial.

O desdobramento das potencialidades, limitações, riscos e desafios em eixos de análise facilita a operacionalização, mas exigirá uma correspondente sistematização. Para isto, utilizou-se seis (6) eixos temáticos que estruturaram o próprio diagnóstico técnico: infraestrutural, sociocultural, econômico, turístico, ambiental e institucional. Cada um desses eixos está subdividido em subgrupos de análise (SIEDENBERG, 2010).

Quadro 02- Síntese dos Eixos Temáticos e Subgrupos de Análise Regional

\begin{tabular}{|l|l|}
\hline $\begin{array}{c}\text { Eixos } \\
\text { Temáticos }\end{array}$ & \multicolumn{1}{c|}{ Subgrupos de Análise } \\
\hline Ambiental & $\begin{array}{l}\text { Meio ambiente, fauna e flora, biomas, degradação e conservação de solos, } \\
\text { poluição, desmatamento, impactos ambientais. }\end{array}$ \\
\hline Infraestrutural & Saneamento, energia, comunicações, transporte, habitação e urbanismo. \\
\hline Econômico & $\begin{array}{l}\text { Setor primário, setor secundário, setor terciário, mercado de trabalho, comércio } \\
\text { exterior, gestão pública local. }\end{array}$ \\
\hline Sociocultural & Educação, saúde, justiça e segurança, assistência social, cultura, esporte e lazer. \\
\hline & Patrimônio da humanidade, gastronomia, pesca, esportes náuticos, parques \\
\hline
\end{tabular}




\begin{tabular}{|l|l|}
\hline Turístico & aquáticos, rotas, belezas naturais, turismo rural e religioso. \\
\hline Institucional & $\begin{array}{l}\text { Articulação e relações interinstitucionais, fomento de capital social, planejamento } \\
\text { local e regional. }\end{array}$ \\
\hline
\end{tabular}

Fonte: Adaptado de Siedenberg (2010).

No entanto, além da elaboração da matriz F.O.F.A. por eixos temáticos do PEDR Missões, coube ainda estabelecer a priorização das demandas, e a partir delas a definição das estratégias e seus respectivos projetos de desenvolvimento regionais. Para isso, foi utilizada como estratégia de hierarquização a metodologia da Matriz de Vester, no que tange as fraquezas e ameaças detectadas no processo de construção das Matrizes F.O.F.A. regionais, por eixo temático em análise.

Conforme Rodriguez (2008, p. 32) a ferramenta "Matriz de Vester foi desenvolvida pelo alemão Frederic Vester, em 1983, como uma técnica que facilita a identificação e determinação das causas e consequências de uma situação problema".

Uma boa identificação de problemas garante a formulação de objetivos, de forma clara e precisa, e por sua vez, facilita o planejamento de alternativas para atingi-los. A vantagem da Matriz de Vester [...] está no fato de aportar os elementos suficientes para estabelecer relações de causa-efeito entre os problemas analisados. Isso permite chegar à determinação dos problemas críticos e ativos, os quais requerem maior atenção e uma rápida formulação de alternativas de correção, prevenção e controle (RODRIGUEZ, 2008, p. 32).

Deste modo, evidenciados os principais problemas atuantes no desenvolvimento de uma determinada região deve-se, de forma consensuada, contemplar as inter-relações existentes entre eles, buscando estabelecer as relações de causalidade, que de certa forma, possam ajudar explicar os entraves diagnosticados. De acordo com Rodriguez (2008, p. 32) "uma matriz é uma série de linhas e colunas, sendo as primeiras horizontais e as segundas verticais". Colocamse problemas identificados nos dois sentidos (ativos e passivos) e, em uma mesma ordem, previamente identificada.

Depois de estruturada, a matriz deve ser preenchida, considerando uma escala de valoração, com grau de causalidade entre as variáveis. Este grau de causalidade é representado pelas seguintes valorações: a) $0=$ não é causa; b) $1=$ é causa indireta; c) 2 = é causa medianamente direta; e, d) 3 = é causa muito direta (RODRIGUEZ, 2008, p. 32). 
Quadro 03- Matriz de Vester

\begin{tabular}{|l|c|c|c|c|c|c|c|}
\hline Problemas & Prob 1. & Prob 2. & Prob 3. & Prob 4. & Prob 5. & Prob 6. & Total Ativos \\
\hline Problema 1. & & 2 & 3 & 1 & 2 & 1 & $\mathbf{9}$ \\
\hline Problema 2. & 0 & & 3 & 1 & 2 & 2 & $\mathbf{8}$ \\
\hline Problema 3. & 2 & 3 & & 2 & 0 & 2 & $\mathbf{9}$ \\
\hline Problema 4. & 3 & 2 & 1 & & 0 & 1 & $\mathbf{7}$ \\
\hline Problema 5. & 2 & 1 & 3 & 1 & & 1 & $\mathbf{8}$ \\
\hline Problema 6. & 1 & 1 & 3 & 0 & 1 & & $\mathbf{6}$ \\
\hline Total Passivos & $\mathbf{8}$ & $\mathbf{9}$ & $\mathbf{1 3}$ & $\mathbf{5}$ & $\mathbf{5}$ & $\mathbf{7}$ & $\mathbf{4 7}$ \\
\hline
\end{tabular}

Fonte: Adaptado de Rodriguez (2008, p. 34).

Segundo Rodriguez (2008, p. 33) para preencher a matriz, faz-se a seguinte relação: "que grau de causalidade tem o problema 1 sobre o problema 2?; que grau de causalidade tem o problema 1 sobre o problema 3?; que grau de causalidade tem o problema 1 sobre o problema n?". Assim, "este processo de preenchimento realiza-se, horizontalmente, partindo da primeira linha, e assim sucessivamente, até preencher todas as linhas da matriz com os respectivos valores" (RODRIGUEZ, 2008, p. 33). Além disto, nota-se que há células vazias na matriz, pois não pode haver relação de causalidade de um problema, com ele mesmo.

Conforme explicitado no Quadro 03, a relação de causalidade elaborada na Matriz de Vester apresenta o cálculo de ativos e passivos. Na soma das linhas horizontais encontram-se o total de ativos de cada problema e, na soma vertical, o total de passivos respectivos a cada problema. A partir da elaboração da matriz, a próxima etapa é referente à classificação dos problemas, com a construção do gráfico de coordenadas cartesianas, divididos em dois eixos (no eixo horizontal, o total ativo e, no eixo vertical, o total passivo), com quatro quadrantes: 1) quadrante superior direito - problemas críticos; 2) quadrante superior esquerdo - problemas passivos; 3) quadrante inferior esquerdo - problemas indiferentes; 4) quadrante inferior direito - problemas ativos (RODRIGUEZ, 2008). 
Figura 06- Gráfico de Coordenadas Cartesianas

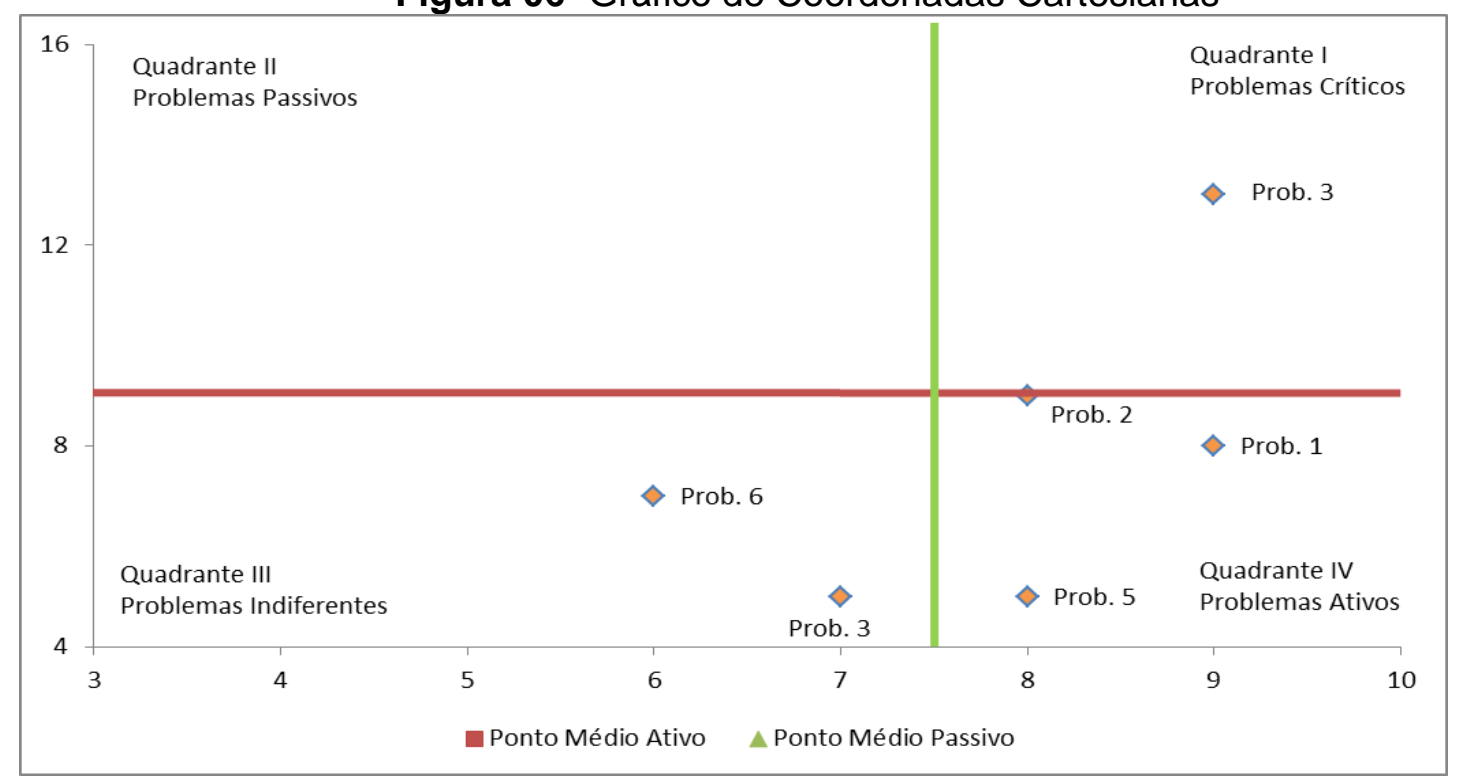

Fonte: Adaptado de Rodriguez (2008, p. 35).

De acordo com Rodriguez (2008, p. 36), os problemas críticos possuem um valor total alto de ativos e de passivos, apresentando muitas causas e consequências, e deles dependem os resultados finais; os problemas ativos têm um valor em ativos alto e um total de passivos baixo, representando uma alta influência causal sobre a maioria dos restantes, mas, no entanto, não são causados por outros - são pontos chaves, e deste modo, requerem atenção e manejo cruciais. Os problemas passivos são aqueles que apresentam um total passivo alto e um total ativo baixo, o que significa que tem pouca influência causal - utilizam-se como indicadores de mudança e de eficiência da intervenção de problemas ativos e, por fim os problemas indiferentes possuem um total de ativos e de passivos de baixo valor, e, portanto, detém uma baixa prioridade dentro da análise.

Conforme a escala de prioridade estabelecida, de acordo com a metodologia da Matriz de Vester, foram considerados os problemas críticos e os problemas ativos, cujo os quais possuem maior efeito-causalidade, identificados pela sociedade, sobre o desenvolvimento da região do Corede Missões.

A definição das estratégias que abrange o processo de construção do PEDR do Corede Missões pautou-se em circunscrever as áreas que apresentam carências latentes, capturadas através da metodologia de Vester, capazes em influenciar no processo de melhoria da qualidade de vida da população da referida região. Considerando a sua realidade, delineada por meio da interpretação dos dados no 
diagnóstico técnico ${ }^{9}$. Tais problemáticas levaram posteriormente a construção de projetos de desenvolvimento, referentes a cada eixo de análise supracitado do Corede Missões.

Deste modo, as ações visaram atender as carências referendadas pela sociedade, que transitaram entre os diferentes eixos em análise, anteriormente estabelecidas, e, que exigiu a necessidade de definição de quatro grandes estratégias regionais (PEDR Missões), distribuídas em: 1) Infraestrutural; 2) Sociocultural; 3) Competividade e Sustentabilidade Ambiental das Cadeias Produtivas; e, 4) Articulação, Governança e Planejamento Territorial.

Por fim, o modelo proposto no plano estratégico territorial está embasado nas diretrizes definidas pelo Fórum dos Corede's e na metodologia adotada pela maioria dos vinte e oito (28) Corede's do Rio Grande do Sul para elaboração dos seus respectivos PEDR's a partir de 2009 (SIEDENBERG, 2010).

\section{NOTAS FINAIS}

A atualização do Plano Estratégico de Desenvolvimento Regional do Corede Missões (PEDR Missões) foi construído pelos princípios da horizontalidade. A participação e a mobilização da sociedade foi o vetor indutor do PEDR Missões. $O$ plano foi formatado através de um conjunto de atores sociais, agentes, lideranças e instituições - conselhos municipais de desenvolvimento (Comude), secretarias municipais, associações comerciais, sindicatos, associações, entidades de classe e população em geral.

Durante as mais de quarenta (40) oficinas de direcionamento estratégico municipais, regionais e setoriais, realizadas em todos os municípios da região das Missões, foram reunidos aproximadamente seiscentos e cinquenta (650) atores sociais que puderam expressar sua visão quanto às dimensões das F.O.F.A.'s municipais e regionais, das estratégias e do estabelecimento de prioridades, com enfoque no desenvolvimento do território regional.

O processo de atualização do PEDR Missões percorreu a totalidade dos municípios pertencentes ao território missioneiro, para debater sobre as fortalezas, oportunidades, fraquezas e ameaças, de modo a direcionar estratégias de

\footnotetext{
${ }^{9}$ Para a definição das problemáticas regionais utilizou-se o diagnóstico técnico, mais especificamente a matriz F.O.F.A. regional por dimensão (infraestrutural, sociocultural, turística, ambiental, econômica e institucional). Assim, a partir desta, utilizou-se a metodologia da matriz de Vester (relação de causalidade - por priorização), que destacou os principais problemas regionais, no que tange as suas mais latentes fraquezas e ameaças para o desenvolvimento da região. Portanto, as estratégias, as ações e os ante-projetos regionais terão o foco concentrado nestas problemáticas, no sentido de minimizar as fraquezas e ameaças identificadas pela sociedade.
} 
desenvolvimento, na busca de espaços mais justos e menos desiguais, constituindose, como instrumento indutor do aprimoramento de um sistema de governança territorial.

Enfim, como resultado da participação social, e do regramento metodológico seguido, foram construídas quatro (4) grandes estratégias regionais, as quais originaram cinquenta e seis projetos (56) e ações futuras, hierarquizadas, visando atacar os entraves identificados pela sociedade, visando o desenvolvimento da Região do Corede Missões.

\section{REFERÊNCIAS BIBLIOGRÁFICAS}

BECKER, D. F. (Org.). Pró-RS II - por uma organização social pró-desenvolvimento do Rio Grande do Sul. Santa Cruz do Sul (RS): EDUNISC, 2002.

BECKER, Berta K. O Uso Político do Território: questões a partir de uma visão do terceiro mundo. In: BECKER, Berta K.; COSTA, Rogério K.; SILVEIRA, Carmem B.; (orgs) Abordagens Políticas da Espacialidade. Rio de Janeiro: UFRJ, 1983.

BECKER, B. K. A geopolítica na virada do milênio: logística e desenvolvimento sustentável. In: CASTRO, I. E.; GOMES, P. C. da C. (Org.). Geografia: conceitos e temas. Rio de Janeiro: Bertrand Brasil, 1995. p. 271-307.

BECKER, D.; BANDEIRA, P. Programa de desenvolvimento integrado e sustentável da mesorregião da metade Sul. Santa Maria: Pallotti, 2003.

BOISIER, Sérgio. Centralización y descentralización territorial en el processo decisorio del sector público. Santiago de Chile: ILPES/CEPAL, 1995.

BÜTTENBENDER, Pedro L.; SIEDENBERG, Dieter R.; ALLEBRANDT, Sergio L. Coredes: estruturação, articulações intra e inter-regionais, referenciais estratégicos e considerações críticas. In:

BÜTTENBENDER, Pedro Luís. Prácticas innovadoras de gestión del desarollo de región de frontera: el caso de la Región del Noroeste del Estado do Rio Grande do Sul. Tese de Doutorado em administração. Orientador. Dr. Jorge Oneide Sausen Facultad de Ciências Económicas, Universidad Nacional de Misiones, Posadas/MI/Argentina. 2014.

CARDOSO JR. J. C.; MELO, Valdir. Reinvenção do planejamento governamental no Brasil Planejamento no Brasil: auge, declínio e caminhos para a reconstrução. IPEA.http://www.ipea.gov.br/agencia/images/stories/PDFs/livros/livros/livro_dialogosdesenvo 104.pdf.

CARGNIN, Antônio P. Políticas de desenvolvimento regional no Rio Grande do Sul: vestígios, marcas e repercussões territoriais. Tese (Doutorado) - Programa de PósGraduação em Geografia, Universidade Federal do Rio Grande do Sul, Porto Alegre, 2011.

CODETER MISSÕES. Colegiado de desenvolvimento territorial CODETER/MISSÕES. Secretaria de Desenvolvimento Territorial - SDT Ministério de Desenvolvimento Agrário MDA. Plano Territorial de Desenvolvimento Sustentável PTDRS - Território das Missões. Santo Ângelo, 2006.

CONSÓRCIO BOOZ ALLEN. Estudo sobre desenvolvimento regional e logística de transportes no RS. Projeto Rumos 2015. Porto Alegre (RS): FIPE/HLC, 2005.

COREDE MISSÕES. Planejamento estratégico regional. EdiURI. Santo Ângelo: 2010.

COREDES-RS. PRÓ-RS V: propostas estratégicas para o desenvolvimento regionais no estado do RS (2015-2018). Lajeado: Editora da Univates, 2014. 
CROCCO, M. e DINIZ, C. C. Economia Regional e Urbana - contribuições recentes. Belo Horizonte: Ed.UFMG, 2006. p. 195-223.

ETGES, Virgínia Elisabeta. A região no contexto da globalização: o caso do Vale do Rio Pardo. In: VOGT, Olgário e SILVEIRA, Rogério. Vale do Rio Pardo: (re)conhecendo a região. Santa Cruz do Sul: Edunisc, 2001.

ETGES, Virgínia Elisabeta. Desenvolvimento Regional sustentável: o território como paradigma. REDES, Santa Cruz do Sul, v.10, n.3, p.47-55, set/dez. 2005.

ETGES, Virginia Elisabeta; DEGRANDI, José Odim. Desenvolvimento regional: a diversidade regional como potencialidade. RBDR, Blumenau,v.1, n.1, p. 85-94, abril. 2013.

FERNÁNDEZ, Victor Ramiro e BRANDÃO, Carlos. Escalas y políticas del desarrolllo regional: Desafios para América Latina. Buenos Aires: Miño y Dávila Editores, 2010.

FERREIRA, L. da C.; FERREIRA, L. da C. Limites ecossistêmicos: novos dilemas e desafios para o estado e para a sociedade. In: HOGAN, D. J.; VIEIRA, P. F. Dilemas socioambientais e desenvolvimento sustentável. Campinas, SP: UNICAMP, 1995. p. 13-36.

FILIPPIM, Eliane Salete. RÓTULO, Daniel. Governança, participação social e diálogo federativo: o caso de Santa Catarina In: Política e Planejamento Regional - Uma Coletânea/Rainer Randolph e Hermes Magalhães Tavares, organizadores. Brasília: Gráfica Movimento, 2013.

FUNDAÇÃO DE ECONOMIA E ESTATÍSTICA DO ESTADO DO RIO GRANDE DO SUL. Disponível em: http://www.fee.rs.gov.br/, Acesso em 26 de setembro de 2014. (FEE).

FUNDAÇÃO DE ECONOMIA E ESTATÍSTICA DO ESTADO DO RIO GRANDE DO SUL. $<$ <ttp://www.fee.tche.br/sitefee/pt/content/capa/index.php> Acesso em: 03.out.2015.

IBGE. Instituto Brasileiro de Geografia e Estatística. Acesso em 12 de junho de 2014, http://www.ibge.com.br/home/.

IPEA. Instituto de Pesquisa Econômica Aplicada. Disponível em: < http://www.ipea.gov.br/portal/>. Acessado em: 15 junho, 2016.

NIEDERLE, P. A.; WESZ JUNIOR, V. J. A agroindústria familiar da região Missões; construção de autonomia e diversificação dos meios de vida. Santa Cruz do Sul. REDES. V. 14, n. 03, p.75 - 102, set./dez.. 2009.

POLACINSKI, E. et al.. Plano de Desenvolvimento do APL da Agroindústria Familiar das Missões (RS). Fundação Regional Integrada. Santo Ângelo, 2014.

RODRIGUEZ, Ivonne A. V.. A aplicação da modelagem computacional na identificação de problemas ambientais. Revista Didática Sistêmica. volume 7, janeiro a junho, Universidade Federal de Rio Grande, 2008

SANTOS, Milton. A natureza do Espaço - técnica e tempo, razão e emoção. São Paulo: Hucitec, 2006.

SIEDENBERG, Dieter R.; BÜTTENBENDER, Pedro L.; ALLEBRANDT, Sergio L. A trajetória do planejamento governamental no Rio Grande do Sul: dos primórdios aos Coredes. In: DALLABRIDA, Valdir R. (Org.). Governança Territorial e Desenvolvimento: Descentralização Político-Administrativa, Estruturas Subnacionais de Gestão do Desenvolvimento e Capacidades Estatais, Rio de Janeiro, Editora Garamond, 2011.

SEPLAN. Governo Estado do Rio Grande do Sul. PERFIS- REGIÕES FUNCIONAIS DE PLANEJAMENTO. Secretaria do Planejamento e Desenvolvimento Regional - Departamento de Planejamento Governamental. Porto Alegre, 2015.

SECRETARIA DOS TRANSPORTES DO RIO GRANDE DO SUL. Divulgação Jornal do Comércio. Disponível em http://jcrs.uol.com.br/_conteudo/2016/07/economia/508631aeroporto-de-santo-angelo-precisa-se-adequar-para-operar-voos-da-azul.html Acessado em 01 de agosto de 2016. 
ZUANAZZI, P. T. A Transição Demográfica do RS: Causas e Consequências. Fundação de Economia e Estatística. Porto Alegre, 2015.

\section{NOTAS DE AUTOR}

\section{CONTRIBUIÇÃO DE AUTORIA}

Daniel Claudy da Silveira - Concepção. Coleta de dados da pesquisa, análise dos dados, elaboração do manuscrito, revisão e aprovação da versão final do trabalho.

Berenice Beatriz Rossner Wbatuba - Análise dos dados, elaboração do manuscrito, revisão.

Luis Claúdio Villani Ortiz - Concepção. Coleta de dados, análise de dados, elaboração do manuscrito.

\section{FINANCIAMENTO}

Secretaria de Planejamento, Governança e Gestão (SPGG), através do convênio do Governo do Estado do Rio Grande do Sul, por intermédio da Secretaria de Planejamento, Mobilidade de Desenvolvimento Regional e o Fórum dos Conselhos Regionais de Desenvolvimento do Estado do Rio Grande do Sul. Convênio n. 1636/2015.

\section{CONSENTIMENTO DE USO DE IMAGEM}

Não se aplica.

\section{APROVAÇÃO DE COMITÊ DE ÉTICA EM PESQUISA}

Não se aplica.

\section{CONFLITO DE INTERESSES}

Não se aplica.

\section{LICENÇA DE USO}

Este artigo está licenciado sob a Licença Creative Commons CC-BY. Com essa licença você pode compartilhar, adaptar, criar para qualquer fim, desde que atribua a autoria da obra.

\section{HISTÓRICO}

Recebido em: 13-03-2020

Aprovado em: 06-04-2020 